\title{
Social Networking Services-Based Communicative Care for Patients with Diabetes Mellitus in Korea
}

Hun-Sung Kim ${ }^{1,2}$; Yoo Jin Jeong ${ }^{1}$; Sun Jung Baik'; So Jung Yang'; Tong Min Kim'; Hyunah Kim³; Hyunyong Lee ${ }^{4}$; Seung-Hwan Lee²; Jae Hyoung Cho²; In-Young Choi ${ }^{1}$; Kun-Ho Yoon ${ }^{1,2}$

1Department of Medical Informatics, College of Medicine, The Catholic University of Korea, Seoul, Republic of Korea;

${ }^{2}$ Division of Endocrinology and Metabolism, Department of Internal Medicine, Seoul St. Mary's Hospital, College of Medicine, The Catholic University of Korea, Seoul, Republic of Korea;

${ }^{3}$ College of Pharmacy, Sookmyung Women's University, Seoul, Republic of Korea;

${ }^{4}$ Clinical Research Coordinating Center, Catholic Medical Center, The Catholic University of Korea, Seoul, Republic of Korea

\section{Keywords}

Diabetes mellitus, personal health records, communication, networks, home health, patient selfcare, home care and e-health, consumer health

\section{Summary}

Objectives: Social networking services (SNS)-based online communities are good examples of improving quality of care by incorporating information technology into medicine. Therefore, we created an SNS-based community care webpage for communication among patients with diabetes mellitus (DM). We aimed to identify what diabetic patients wanted to know and were interested in by analyzing their posts and classified content in which users were interested.

Methods: As opposed to the existing physician-focused health information websites, we built a patient-focused experience exchange website, "I love insulin (http://www.iloveinsulin.co.kr)." The DM communication webpage was divided into "My Web-Chart," "My community-free board," and "Life \& Health." The contents analysis targeted users' postings, and replies were classified by theme from May 2012 to June 2013. The data included number of questions asked, answers, and question-to-answer (QA) ratio in each category.

Results: A total of 264 patients registered on the "I Love Insulin" website. The most frequent topic of posts classified as questions were about diabetes itself $(23 \%)$, diet $(22 \%)$, and glucose levels $(19 \%)$. Conversely, most answers and information provided by users were about daily life with no relationship to diabetes mellitus $(54 \%)$. While there were many questions about diet, there were very few answers $(2 \%)$. Whereas there was much provision of knowledge about general DM, sharing diet information was rare. The ratios of answers to questions on diet (ratio $=0.059,1 / 17)$, glucose level $($ ratio $=0.067,1 / 15)$, insulin regulation $(r a t i o=0.222,2 / 9)$ and webpage (ratio $=0.167,1 / 6)$ were significantly low compared to DM itself (all $p<0.001$ ).

Discussion: Patients in Korea with DM tend to have insufficient knowledge about diet and insulin regulation; continuously providing diet and insulin regulation information are desirable. It is hoped that the patients would be motivated to participate actively by "knowledge sharing." Through this process, patients learn about their diseases not from the physicians but from among themselves. 


\section{Correspondence to:}

Kun-Ho Yoon, M.D., Ph.D.

Department of Medical Informatics,

College of Medicine,

The Catholic University of Korea,

Republic of Korea

222, Banpo-daero, Seocho-gu

Seoul, 06591

Republic of Korea

Tel: +82-2-2258-8262

Fax: +82-2-2258-8297

E-mail; yoonk@catholic.ac.kr
Appl Clin Inform 2016; 7: 899-911

http://dx.doi.org/10.4338/ACl-2016-06-RA-0088

received: June 11, 2016

accepted: August 22, 2016

published: September 28, 2016

Citation: Kim H-S, Jeong YJ, Baik SJ, Yang SJ, Kim TM, Kim H, Lee H, Lee S-H, Cho JH, Choi I-Y, Yoon K-H. Social networking services-based communicative care for patients with diabetes mellitus. Appl Clin Inform 2016; 7: 899-911

http://dx.doi.org/10.4338/ACl-2016-06-RA-0088 


\section{Introduction}

Internet users obtain health information more commonly by searching through web portals than from their physicians [1]. In the United States, about 70-80\% of American Internet users search for health information [2]. In addition, health information obtained through the Internet helps the users in the actual decision-making process [3]. Recently, social networking services (SNS) are drawing attention as mediums of prompt health information. [4-9]. Because SNS enable direct communication among users without much knowledge about computers [10] and allow them to easily access health information, users can share their opinions bi-directionally without limitations of time and space and obtain a substantial amount of health information. Therefore, it would be beneficial if health information and health content were efficiently supplied via SNS, and active participation and lifestyle modification of Internet users (medical consumers) were encouraged.

Many websites and applications targeting patients with diabetes mellitus (DM) have been released recently, as this patient population is increasing rapidly [11-13]. In fact, potential blood glucose management and clinically positive effects of using information technology (IT), such as medical websites or apps are constantly being reported [14-17]. Many recent studies address communication between doctors and patients with the help of IT, [14-15, 18-21] and physicians unilaterally convey health information to the patients. Although medical consumers are gradually obtaining more knowledge, the incidence of chronic diseases is still increasing significantly [22]. Excess knowledge about exercise and diet is better than not having any knowledge at all. However, chronic diseases increase not because the patients do not know much about diet or exercise, but because they do not implement what they know [23-25]. Therefore, what really matters is actively helping people bring about behavioral changes rather than just teaching them about these changes [25-27]. This would help in motivating patients to adopt the right habits and regime for their disease management. This study attempts to bring about active behavioral changes in patients by providing them a platform for sharing their challenges and knowledge about blood glucose management. In view of this, it would not be effective for medical consumers to simply gain more knowledge - medical consumers need to be active in online communities when considering their management of health risk factors. There seems to be a need of a platform to share information among patients, not just between patients and doctors. In fact, there are many online communities about diabetes formed by the patients themselves, and not by doctors. However, patients in these communities mainly focus on sharing their personal stories rather than how to manage blood glucose levels. There is also a lot of pressure about accuracy and credibility [28] of the health information provided on these websites, besides its proper functioning. Moreover, there could be contents for advertisement or untested health information on these websites as well. In addition, analyzing information shared among patients about blood glucose management could allow us to identify the needs of patients in managing their blood glucose levels.

Therefore, the primary aim of this study is to develop an SNS-based community care webpage based on communication among patients with DM. We also classified and confirmed the content of posts on this site in which users (patients with DM) are interested or have questions based on their difficulties. By providing proper feedback for difficult situations or answers to questions from users, we hoped to be of help to patients. We also hope to change medical consumers into active participants in addition to providing an information system for basic health information and knowledge.

\section{Materials and Methods}

\subsection{Establishment of DM Communication Webpage (http://www.ilovein sulin.co.kr)}

In contrast to the existing health information websites, we emphasized creating a patient-focused experience exchange website rather than a physician-focused one. "I love insulin," the DM communication webpage we built, was divided into "My Web-Chart," "My community-free board." and "Life \& Health" ( Figure 1). In "My Web-Chart", users can record blood glucose management data. In "Life \& Health," physicians provide DM information to users. We added patient-patient bulletin 
board "My community-free board" for the users to share their opinions and feelings for the purpose of this study. "My community-free board" enables users to communicate and share their experiences.

Patients with DM who receive insulin injections can record their own blood glucose levels and HbAlc values under the "My Web-Chart" menu. In this menu, various data are recorded with other patients' average values for comparison. It enables the patients to compare with others using various searches and methods and to accurately understand their current blood glucose status. This is intended to motivate the members of the website. The users can find other patients with the same type of diabetes, blood glucose status, and health condition under the "My community-free board" menu where they can discuss the difficulty of blood glucose management and exchange useful information with one another. In the "My community-free board" menu, only users can post notes on the website; the medical staff members do not intervene in the conversations among patients. Users are able to check the comments and respond and can be registered as "favorite friends." If users click on others' profile pictures, they can find information on age, DM duration, hospital, and HbA1c values of other users. It also allows users to register another user as their favorite ( $>$ Figure 2). Online users could use keywords such as DM type, duration, or treatment type to search for others' comments of interest. "Life \& Health" comprises information about patients with DM and insulin treatment. In the "Life and Health" menu, physicians who have their own private hospitals can write a column or update medical opinions under the manager's permission. To convey accurate and reliable information, patients cannot write but can only read the comments. However, it is possible to write a column about medical controversies and issues on the "My community-free board." The medical staff checked posts on "My community-free board" each week, found out what users were interested in, and posted relevant posts on "Life and Health" Menu.

\subsection{Privacy Protection}

The promotion for the website was made for random visitors to the endocrine internal medicine department in our hospital, but the registration was made at home. The website is not for only appointed hospitals or any patient who is interested could participate. Advertising and marketing for the study was conducted by our hospital. To apply for membership, patients had to sign a consent form and conduct email verification; they did not have to provide their national identification number, patient hospital ID, or real name. The users can search for information on diabetes and related current information. Our study was approved by the institutional review board of the Catholic University of Korea.

\subsection{Analysis of Online Users' Postings}

The content analysis targeted users' postings on "My community-free board" and "Life \& Health" from May 2012 to June 2013. Each post became an analysis unit and its contents were designated as a subject of analysis. The contents were classified by two aspects: purpose (question or answer) and theme (health care, diabetes, etc.). Posts about DM were classified by diet, exercise, and medical themes. Posts with more than two themes were classified by allowing for overlap. In other words, when two topics occurred in one post, two themes could exist. Analysis by word, character, space, and time did not occur; posts were classified by focusing on what users were trying to say. We made various topic categories about DM, education, etc. to classify the writing in advance before classification. To classify the topics, one physician performed the classification and the other physician reviewed it once more to satisfy objectivity and generality. After classification by theme, the number of replies in each theme was confirmed.

\subsection{Statistical Analysis}

The posts were separated by questions and answers and were re-categorized by topic. Checking the numbers by category, we calculated the number of answers per question (QA ratio). Categorical variables were analyzed by chi-square test or exact test. Chi square tests were performed by comparing DM QA ratio as a reference to other categories. All statistical analysis were done with SAS version 9.4 (SAS Inc., Cary, NC) and p-values less than 0.05 were considered statistically significant. 


\section{Results}

\subsection{Analysis of "My Web-Chart" Menu}

A total of 264 patients registered for the "I Love Insulin" website. Out of these 264 patients, 140 provided personal information so the baseline characteristics were obtained based on that information ( Table 1). The patients comprised 97 male (69.3\%) and 43 female (30.7\%) users. The mean age was $40.7 \pm 11.7$ years; three were above 65 years old. The mean BMI was $27.4 \pm 11.8 \mathrm{~kg} / \mathrm{m}^{2}$. Specifically, there were 23 patients with Type $1 \mathrm{DM}, 85$ patients with Type $2 \mathrm{DM}$, and 12 patients did not answer the question. Twenty patients $(20 / 140,14.3 \%)$ did not know their DM type. DM duration was $8.5 \pm 7.4$ years. Of them, 68 patients $(68 / 140,48.8 \%)$ used only insulin in managing blood glucose and 29 used insulin in combination with oral medication $(29 / 140,20.7 \%)$ for blood glucose control. The rest of the patients were on oral medication only. Some of them had an insulin injection before or were recommended by doctors to receive insulin treatment in the future. The average HbA1c was $8.1 \pm 1.7 \%$.

\subsection{Analysis of "My community-free board" Menu}

Only 33 patients posted at least once. The total number of posts was 222 cases on 457 topics with an average of 42 views per post. When posts were classified by topic, talking about one's heath state including blood glucose condition were the most frequent $(18 \%, 82 / 457)$. Following in order were 77 questions $(17 \%, 77 / 457)$ related to DM, 57 encouragements from other people $(12 \%, 57 / 457), 57$ answers for questions or information delivery (12\%, 57/457), 56 weather-related articles (12\%, $56 / 457)$, and 36 daily life chats $(8 \%, 36 / 457)$. In addition, there were 30 cases of determination of blood glucose management $(7 \%, 30 / 457)$ and 24 cases of self-reflection on recent blood glucose management (5\%, 24/457; Figure 3). Average replies per post were $3.0 \pm 2.1$. The number of replies for questions about insulin and diet had the highest averages at $4.7 \pm 2.3$ and $4.7 \pm 2.2$ respectively. The replies about exercise cures were $3.5 \pm 1.4$. However, those replies were not exactly questions, but more sympathetic content.

The most frequent topic of posts classified as questions were about DM itself, diet, glucose levels, insulin regulation, and exercise ( $\$$ Table 2 ). Conversely, most answers and information provided by users was about daily life with no relationship to DM and the contents on DM itself were about only a third of posts. Replies to other questions were below 7\%. For example, even though questions about diet and glucose level were roughly a fifth of the content, answers to those questions or information provision were very low. The ratios of answers to questions on diet, glucose level, insulin regulation, and webpage were significantly lower than DM itself (all $p<0.001$ ).

\subsection{Analysis of "Life and Health" Menu}

A total of 24 posts were written by doctors, nurses and nutritionists employed at Seoul St. Mary's Hospital in Korea. Post topics in the early stages were mainly instructions and insulin dosage regulation, fitting the purpose of this site. However, as posts included in "My community-free board" were checked monthly, contents that became issues between users or could not be answered were mainly covered. The average number of people who viewed the post of the total of 24 posts was $118 \pm 39$ and posts about how to regulate basal (265 views) and bolus insulin (176 views) dosages had the most views, consistent with the purpose of the site.

\section{Discussion}

This study aimed to develop a SNS-based community care webpage based on communication among patients with DM. We found that users talked about their blood glucose condition very often; posting many questions about it was the most frequent communication method. The mean BMI $\left(27.4 \pm 11.8 \mathrm{~kg} / \mathrm{m}^{2}\right)$ in our study was similar to that of a previous Korean study $(25.1 \pm 3.5$ $\mathrm{kg} / \mathrm{m}^{2}$ ) [29]. Thus, we assumed that many people who used this website were diabetic and obese. 
Users were concerned about their health (especially diet, exercise, and weight control, etc.), possibly because they had both DM and obesity [30]. Communication on various topics progressed without a medical team in the role of providing an answer or related information. Self-reflection or determination/plan was referenced frequently so that it would contribute somewhat to patients or others changing their minds.

In posts, content about daily life not related to DM was frequent. Users with DM maintained communication with each other by talking about general topics, besides DM (Figure 3). We first thought that people would mostly have a certain degree of knowledge and information about diet and exercises. However, we found that while there were many questions about diet, there were very few answers. Moreover, though there was much provision of knowledge about general DM, sharing of diet information was infrequent. Therefore, we concluded that patients with DM had insufficient knowledge about diet and there was a need to continuously provide diet information. The low responses to blood glucose conditions or insulin control could have been due to difficulties in discussing blood glucose conditions among DM patients. Indeed, previous studies have found that diabetic patients do not really know much about their blood glucose or the medicines that they are taking [31-32]. Thus, even if they are getting insulin injections, they are not likely to know why they are taking them or how to adjust the amount ( $\$$ Table 2 ). To rectify this lack of knowledge, the medical team constantly checked posts on the menu "My community-free board" and posted information on the menu "Life \& Health" about user-generated issues or content on the menu "My community-free board." With this, users expected to obtain better knowledge about DM using this site.

In order to encourage active behavioral change in patients with DM, various methods are suggested [33-34]. Currently, as SNS are utilized in health and medical services, patients are increasingly sharing their personal health-related information online [1]. Our site allows users to manage identities, have conversations, form relationships online, share information, and build reputations for people or products. This has not been achieved under the existing doctor-centered treatment system. This "knowledge-sharing type" of communication among patients is different from the existing "knowledge-conveying type" of communication between physicians and patients. The main service of our patient-to-patient communication presents a method to constantly "self-care" a healthy lifestyle by obtaining information on disease prevention and medical care. We wish this website could be a chance for them to share information and experience about their health condition and blood glucose management besides what is provided by a hospital. A big difference between our website and other online web communities is that in this study medical staffs continuously monitor the posts. This is possible because it's an online webpage operated by a medical team. As previously mentioned in the study, the medical staff continuously monitored postings on "My community-free board" menu on the website and deleted uncertain, untested information and advertisements. Thus, this website can be trusted and relied on by the patients. It is also helpful for the medical staff as they can find out the main interest of the patients, which is the biggest advantage of the website.

The website was made by medical staffs of a certain hospital, but it mainly focuses on sharing information among patients without direct contact between the medical staff and the patients. The only thing the medical staff does is posting common reliable information to answer the patients' questions in "Life and Health" menu, not "My community-free board" menu. There is minimum intervention of the medical staff limited to deleting uncertain or untested information. The study focused more on the patient-patient based online system unlike doctor-patient online based blood glucose management.

Even though it was a site for patients, our webpage was advantageous for doctors as well. As current doctors are only accustomed to treatment in a hospital, they lack practical experience and knowledge for outpatient care. The relationships between physicians and patients still strictly focus on treatment. Physicians now share much more information with patients and interpret it for them rather than perform diagnosis and treatment based on their medical knowledge and clinical experience when dealing with chronic disease. It will also be possible for patients to manage their health between consecutive visits to the hospital [35-37]. Personal and family history in individual health status need to be considered and individualized health information content (diet, exercise, etc.) need to be provided to connect hospital, home, and lifestyles. This form of communication has the benefit of requiring patients' active participation. If medical consumers are provided with objective and adequate information about their health status from the point of questioning their health status to the 
point of visiting the hospital, they may be more effective in maintaining healthy lifestyles [38]. Thus, our website could go beyond forming bonds through sympathy and providing information on daily care (diet and exercise, etc.) to improving patient compliance

Even though there are many advantages pertaining to SNS-based community care websites, our study also has some limitations. First, the shared information may not be accurate or reliable. Because of registration by only e-mail, we cannot be sure that users are genuine DM patients. The effects caused by misleading information might lead to major problems. To minimize this problem, the medical staff continuously examined the "My community-free board" menu on the website. They also attempted to remove posts with serious ethical problems, unclear information, or suspected commercial intent. However, there were no problematic posts during the research period. The more people participate and post, the more effort the medical staff has to put into the website. However, if the community is large and activated, a self-purification process about misleading information is possible, and harmful health-related information would be filtered naturally. However, this does not mean that the self-purification would be flawless. Second, the small sample size is another limitation. This might be due to insufficient promotion for the website. We promoted it to patients who were prescribed insulin in our hospital and they joined in the website if they wanted to, so the number was too small.

\section{Conclusion}

On our website, patients suffering from the same disease, undergoing the same treatment, and with similar interests interact, share, and discuss health information and knowledge. Patients can compare their treatment with that of others and understand their disease status. As the patients share this sense of identity, they obtain new health information and learn about their diseases. Through this process, patients learn about their diseases not from the physicians but from among themselves. It is hoped that the patients would be motivated to participate actively by sharing. To achieve this, a new SNS system that can provide patients with health information through feedback and modeling and in which patients can participate and share information is needed. This is the expected role of " $I$ Love insulin."

Disclosure Statement

No competing financial interests exist.

\section{Conflict of Interest}

No conflicts of interest

\section{Human Subjects Protections}

Since the real names of the users are not used, the physicians are unable to search for the users. Our study did not use any private patient information or possess any possibility of additional physical risks to the patients involved. Owing to the anonymity of the data and the retrospective nature of the study, informed consent was not required. 


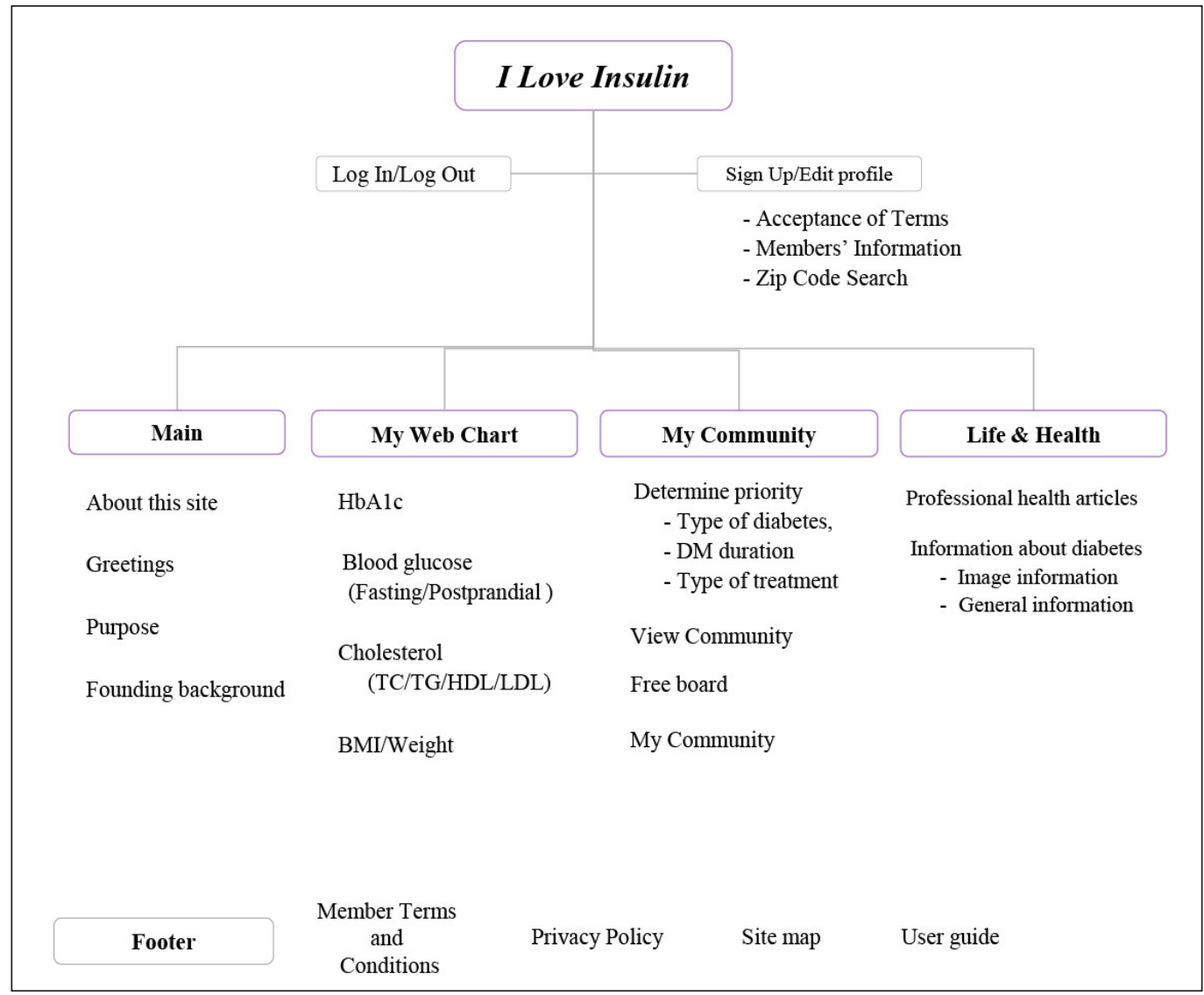

Fig. 1 Web navigation 

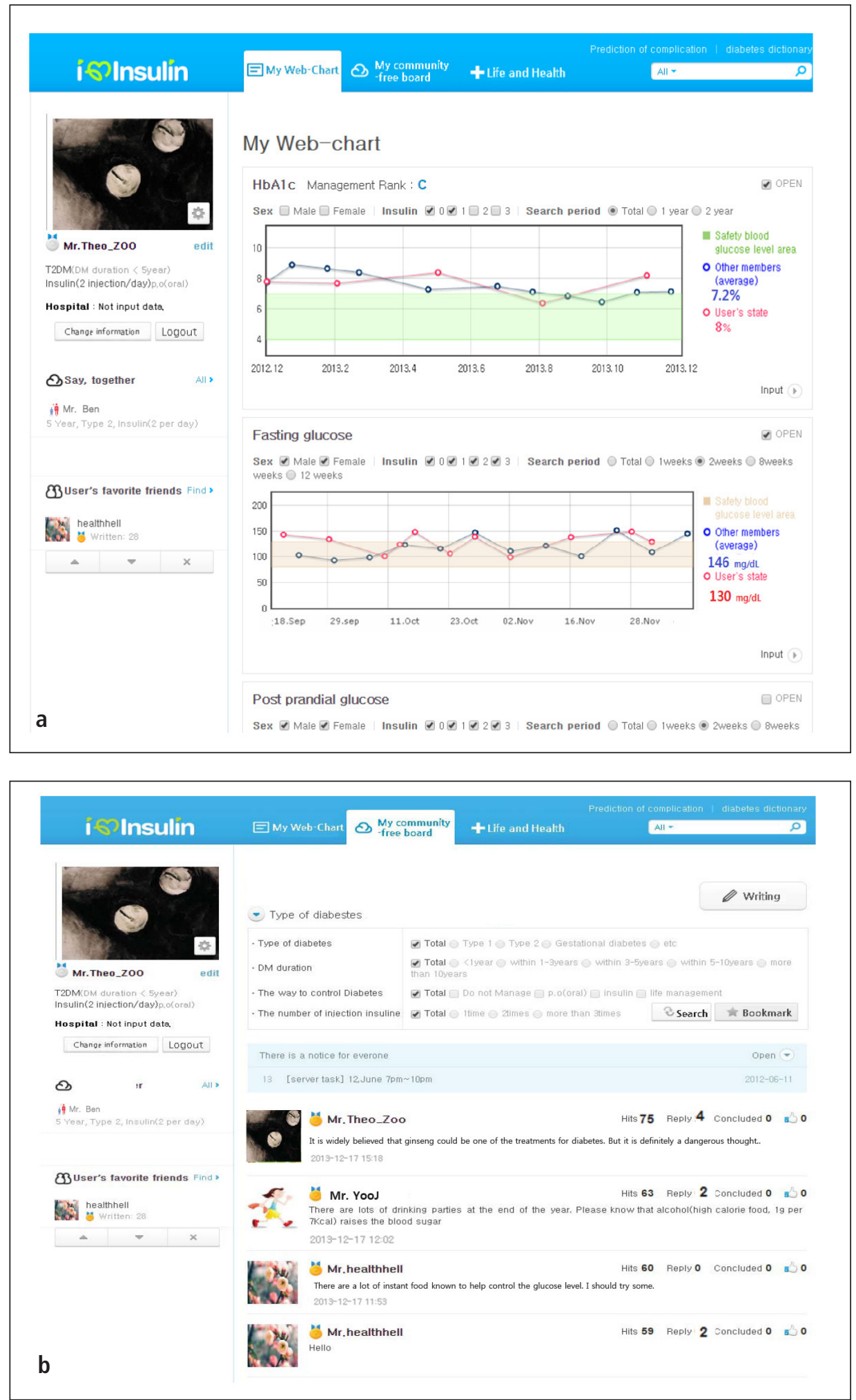

Fig. 2 Examplary site of the screen a. "My Web-Chart" menu b. "My community-free board" menu 


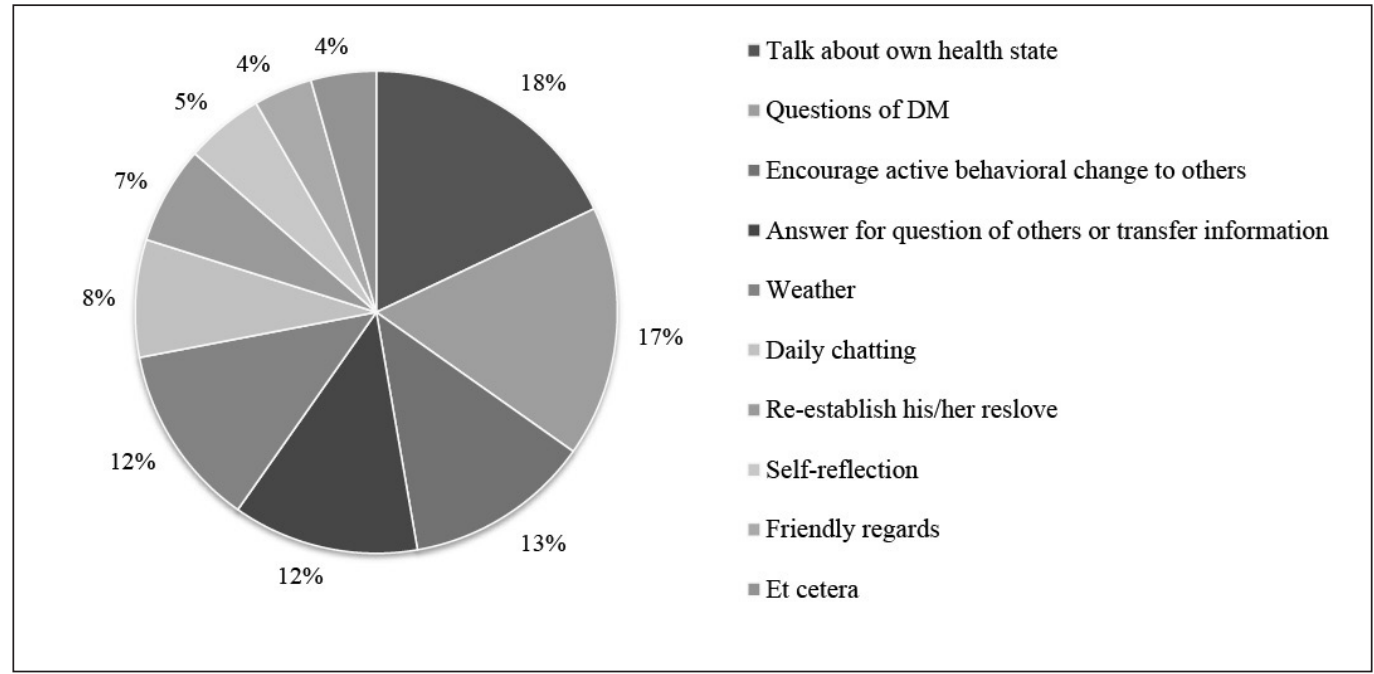

Fig. 3 Detailed list of contents by the "I love insulin" website user 


\begin{tabular}{|l|l|}
\hline Total & 140 users \\
\hline Male, $n(\%)$ & $97(69.3 \%)$ \\
\hline Age, years & $40.7 \pm 11.7$ \\
\hline$>65$ years, $\mathrm{n}(\%)$ & $3(2.1 \%)$ \\
\hline HbA1c, $\%$ & $8.1 \pm 1.7$ \\
\hline BMI (kg/m2) & $27.4 \pm 11.8$ \\
\hline Type of DM & \\
\hline Type 1 DM & $23(16.4 \%)$ \\
\hline Type 2 DM & $85(60.7 \%)$ \\
\hline Not answer & $12(8.6 \%)$ \\
\hline Unknown & $20(14.3 \%)$ \\
\hline DM duration, years & $8.5 \pm 7.4$ \\
\hline DM management & \\
\hline OHA & $43(30.7 \%)$ \\
\hline Only Insulin & $68(48.6 \%)$ \\
\hline Insulin + OHA & $29(20.7 \%)$ \\
\hline
\end{tabular}

Table 1 Baseline characteristics of "I love insulin" website user

Table 2 Detailed list of contents by the "I love insulin" website users

\begin{tabular}{|l|l|l|l|l|}
\hline & Question & Answer & $\begin{array}{l}\text { Answer/Question } \\
\text { ratio }\end{array}$ & p-value \\
\hline Total number, $\mathrm{n}$ & 77 & 57 & 0.741 & \\
\hline Diabetes itself, $\mathrm{n}(\%)$ & $18(23.4 \%)$ & $17(29.8 \%)$ & 0.944 & Reference \\
\hline Diet, $\mathrm{n}(\%)$ & $17(22.1 \%)$ & $1(1.8 \%)$ & 0.059 & $<0.001$ \\
\hline One's glucose levels, $\mathrm{n}(\%)$ & $15(19.5 \%)$ & $1(1.8 \%)$ & 0.067 & $<0.001$ \\
\hline Insulin regulation, $\mathrm{n}(\%)$ & $9(11.7 \%)$ & $2(3.5 \%)$ & 0.222 & $<0.001$ \\
\hline Exercise, $\mathrm{n}(\%)$ & $6(7.8 \%)$ & $4(7.0 \%)$ & 0.667 & $\mathrm{NA}$ \\
\hline Web-page, $\mathrm{n}(\%)$ & $6(7.8 \%)$ & $1(1.8 \%)$ & 0.167 & $<0.001$ \\
\hline No relationship to diabetes mellitus, $\mathrm{n}(\%)$ & $5(6.5 \%)$ & $31(54.4 \%)$ & & $\mathrm{NA}$ \\
\hline Oral medication, $\mathrm{n}(\%)$ & $1(1.3 \%)$ & $0(0.0 \%)$ & & 1.000 \\
\hline
\end{tabular}

*The frequency analysis did not include a case whose ratio was over 1. 


\section{References}

1. http://pewinternet.org/Reports/2011/HealthTopics.aspx

2. Escoffery C, Miner KR, Adame DD, Butler S, McCormick L, Mendell E. Internet use for health information among college students. J Am Coll Health 2005 ; 53(4): 183-188.

3. Wantland DJ, Portillo CJ, Holzemer WL, Slaughter R, McGhee EM. The effectiveness of Web-based vs. non-Web-based interventions: a meta-analysis of behavioral change outcomes. J Med Internet Res 2004; 6(4): e40.

4. Sawesi S, Rashrash M, Phalakornkule K, Carpenter JS, Jones JF. The Impact of Information Technology on Patient Engagement and Health Behavior Change: A Systematic Review of the Literature. JMIR Med Inform 2016; 4(1): e1.

5. Wagner TH, Baker LC, Bundorf MK, Singer S. Use of the Internet for health information by the chronically ill. Prev Chronic Dis 2004; 1(4): A13.

6. Harris JK, Mueller NL, Snider D. Social media adoption in local health departments nationwide. Am J Public Health 2013; 103(9): 1700-1707.

7. Neiger BL, Thackeray R, Van Wagenen SA, Hanson CL, West JH, Barnes MD, Fagen MC. Use of social media in health promotion: Purposes, key performance, i ndicators, and evaluation metrics. Health Promot Pract 2012; 13(2): 159-164.

8. Vance K, Howe W, Dellavalle RP. Social internet sites as a source of public health information. Dermatol Clin 2009; 27(2): 133-136.

9. Shaw RJ, Johnson CM. Health information seeking and social media use on the Internet among people with diabetes. Online J Public Health Inform 2011; 3(1).

10.Lee, M. B., \& Kim, E, J. (2005). A study on the effect of participatory motives and social influence in online community on commitment. The Journal of Information Systems, 14, 191-214.

11. Rhee EJ. Diabetes in Asians. Endocrinol Metab (Seoul). 2015; 30(3): 263-269.

12. Ha KH, Kim DJ. Trends in the Diabetes Epidemic in Korea. Endocrinol Metab (Seoul) 2015; 30(2): 142-146.

13. Jeon JY, Kim DJ, Ko SH, Kwon HS, Lim S, Choi SH, Kim CS, An JH, Kim NH, Won JC, Kim JH, Cha BY, Song KH, Taskforce Team of Diabetes Fact Sheet of the Korean Diabetes Association. Current Status of Glycemic Control of Patients with Diabetes in Korea: The Fifth Korea National Health and Nutrition Examination Survey. Diabetes Metab J 2014;38(3):197-203.

14. Kim HS, Sun C, Yang SJ, Sun L, Li F, Choi IY, Cho JH, Wang G, Yoon KH. Randomized, Open-label, Parallel Group Study to Evaluate the Effect of Internet-based Glucose Management System on Subjects with Diabetes in China. Telemed J E Health 2016 Mar 3. [Epub ahead of print].

15. Kim YJ, Rhee SY, Byun JK, Park SY, Hong SM, Chin SO, Chon S, Oh S, Woo JT, Kim SW, Kim YS. A Smartphone Application Significantly Improved Diabetes Self-Care Activities with High User Satisfaction. Diabetes Metab J 2015; 39(3): 207-217.

16. Kim HS, Choi W, Baek EK, Kim YA, Yang SJ, Choi IY, Yoon KH, Cho JH. Efficacy of the SmartphoneBased Glucose Management Application Stratified by User Satisfaction. Diabetes Metab J 2014; 38(3): 204-210.

17. Cho JH, Chang SA, Kwon HS, Choi YH, Ko SH, Moon SD, Yoo SJ, Song KH, Son HS, Kim HS, Lee WC, Cha BY, Son HY, Yoon KH. Long-term effect of the Internet-based glucose monitoring system on HbAlc reduction and glucose stability: a 30-month follow-up study for diabetes management with a ubiquitous medical care system. Diabetes Care 2006; 29: 2625-2631.

18. Kim HS, Cho JH, Yoon KH. New Directions in Chronic Disease Management. Endocrinol Metab (Seoul) 2015; 30(2): 159-166.

19. Kim HS, Hwang Y, Lee JH, Oh HY, Kim YJ, Kwon HY, Kang H, Kim H, Park RW, Kim JH. Future prospects of health management systems using cellular phones. Telemed J E Health 2014; 20(6): 544-551.

20. Kim HS, Lee KH, Kim H, Kim JH. Using mobile phones in healthcare management for the elderly. Maturitas 2014;79:381-8.

21.Suh S, Jean C, Koo M, Lee SY, Cho MJ, Sim KH, Jin SM, Bae JC, Kim JH. A Randomized Controlled Trial of an Internet-Based Mentoring Program for Type 1 Diabetes Patients with Inadequate Glycemic Control. Diabetes Metab J 2014; 38(2): 134-142.

22. Anderson G, Horvath J. The growing burden of chronic disease in America. Public Health Rep 2004; 119(3): 263-270.

23.Deakin, T., McShane, CE, Cade JE, Williams RD. Group based training for self-management strategies in people with type 2 diabetes mellitus. Cochrane Database Syst Rev 2005; (2): CD003417.

24. Steed L, Cooke D, Newman S. A systematic review of psychosocial outcomes following education, selfmanagement and psychological interventions in diabetes mellitus. Patient Educ Couns 2003; 51(1): 5-15. 
25.Plack K, Herpertz S, Petrak F. Behavioral medicine interventions in diabetes. Curr Opin Psychiatry 2010; 23(2): 131-138.

26. Channon SJ, Huws-Thomas MV, Rollnick S, Hood K, Cannings-John RL, Rogers C, Gregory JW. A multicenter randomized controlled trial of motivational interviewing in teenagers with diabetes. Diabetes Care 2007; 30: 1390-1395

27. Channon S, Smith VJ, Gregory JW. A pilot study of motivational interviewing in adolescents with diabetes. Arch Dis Child 2003; 88: 680-683.

28. Lee C, Jung Y, Jung J, Won D. Dynamic user reliability evaluation scheme for social network service. Journal of the Korea Institute of Information Security and Cryptology 2013(3): 157-168 [Korean].

29. Lee DH, Jung KY, Park KS, Kim KM, Moon JH, Lim S, Jang HC, Choi SH. Characterization of Patients with Type 2 Diabetes according to Body Mass Index: Korea National Health and Nutrition Examination Survey from 2007 to 2011. Endocrinol Metab (Seoul) 2015; 30(4): 514-521.

30. Kim MK, Lee WY, Kang JH, Kang JH, Kim BT, Kim SM, Kim EM, Suh SH, Shin HJ, Lee KR, Lee KY, Lee SY, Lee SY, Lee SK, Lee CB, Chung S, Jeong IK, Hur KY, Kim SS, Woo JT, Committee of Clinical Practice Guidelines, Korean Society for the Study of Obesity. 2014 Clinical Practice Guidelines for Overweight and Obesity in Korea. Endocrinol Metab (Seoul) 2014; 29(4): 405-409.

31. Kwon OB, Yu JH, Kim KK, Kang HC, Youn BB. How Many Diabetes Patients Know the Name of Hypoglycemic Agents They Are Taking? J Korean Acad Fam Med 2005; 26: 456-463 [Korean].

32. Kim HS. A survey of knowledge of diabetes in patients with type 2 diabetes. J Korean Acad Funda Nurs 2004: 11(1); 67-73 [Korean].

33. Kim HS, Kim H, Lee SH, Lee KH, Kim JH. Current clinical status of and obstacles to telehealth in Korea. Healthc Inform Res 2015; 21(4): 244-250.

34. Ohn JH, Lee JH, Hong ES, Koo BK, Kim SW, Yi KH, Moon MK. Subjective Assessment of Diabetes SelfCare Correlates with Perceived Glycemic Control but not with Actual Glycemic Control . Diabetes Metab J 2015; 39(1): 31-36.

35. Bell AM, Fonda SJ, Walker MS, Schmidt V, Vigersky RA. Mobile phone-based video messages for diabetes self-care support. J Diabetes Sci Technol 2012; 6(2): 310-319.

36. Kim SI, Kim HS. Effectiveness of mobile and internet intervention in patients with obese type 2 diabetes. Int J Med Inform 2008; 77(6): 399-404

37.Ly KH, Carlbring P, Andersson G. Behavioral activation-based guided self-help treatment administered through a smartphone application: study protocol for a randomized controlled trial. Trials 2012; 13: 62.

38. Im JH, Lee KH, Paik SK. Influence of Physician's Communication Style and Quality, and Physician-Patient Relationship on Patient Satisfaction. Korean J Hosp Manag 2009: 14(3); 83-103 [Korean]. 